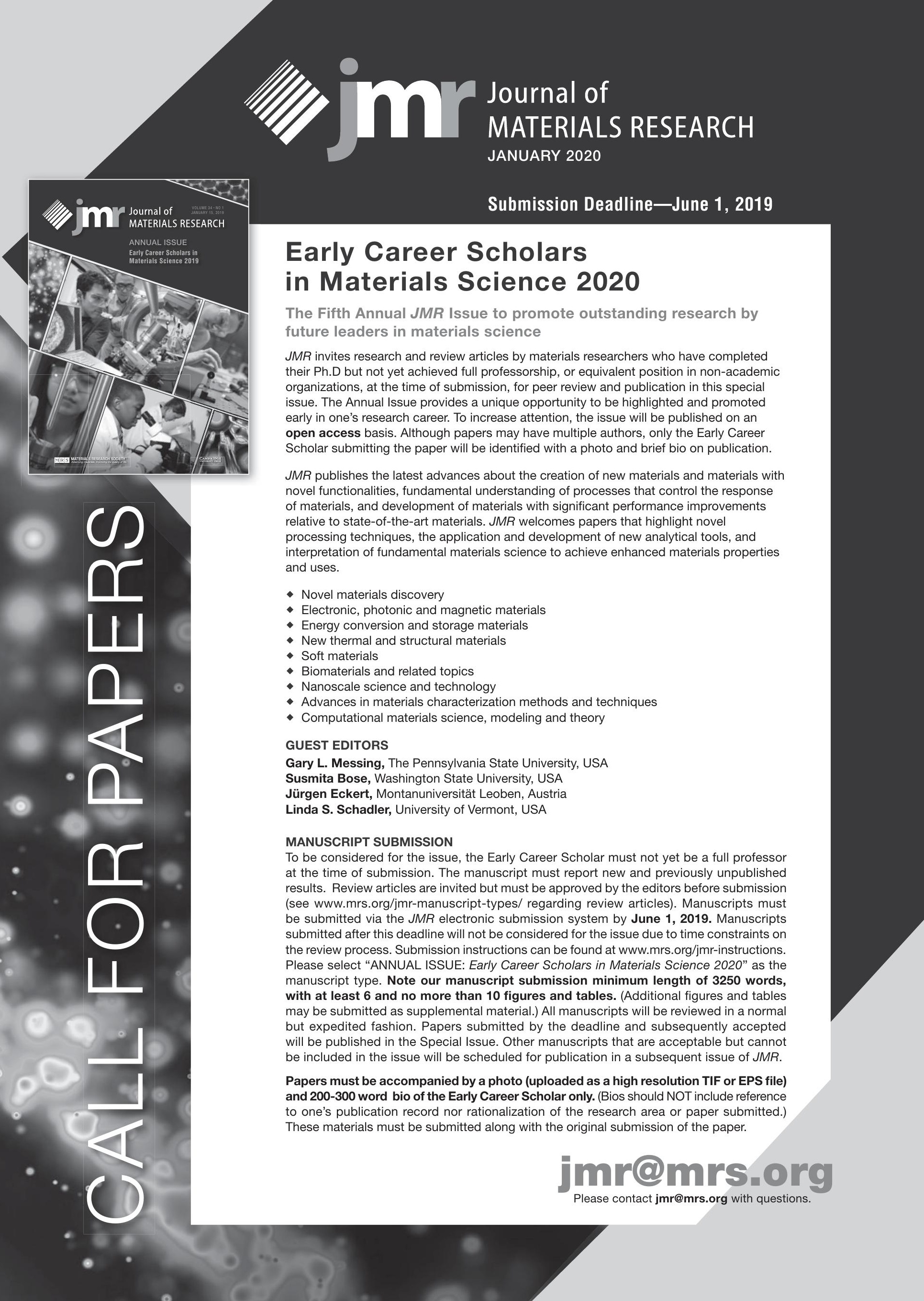




\section{II in $\mathrm{mr}$ FOCUS ISSUE • FEBRUARY 2020}

\section{Advances in Battery Technology: Material Innovations in Design and Fabrication}

The increasing demand for clean energy is a primary force driving the battery industry's innovations in such aspects as long cycle life, wide working temperature, and the search for inexpensive materials with high energy density. Developing novel materials and scalable production processes is essential for the advancement of battery technologies. High-performance materials fabricated by processes with high production yield, repeatable product quality, and facile equipment requirement are greatly favored in both scientific exploration and practical applications. Production of components including electrodes, electrolytes, and separators, is another area of rapid advancement in the field's technology.

This JMR Focus Issue is designed to report the latest advances in battery material innovations and process developments across the industry.

Manuscripts are solicited in the following areas:

- New design for battery materials: cathodes, anodes, electrolytes

- New process development of the material synthesis

- Chemical process simulation

- Process utilizes inexpensive and nontoxic raw materials

- Advanced material characterizations

- New chemistries for energy storage

- Beyond lithium ion

\section{GUEST EDITORS}

Yujia Liang, Argonne National Laboratory, USA

Xuemin Li, National Renewable Energy Laboratory, USA

Haiping Wu, University of California, Los Angeles, USA

Chongmin Wang, Pacific Northwest National Laboratory, USA

\section{MANUSCRIPT SUBMISSION}

To be considered for this issue, new and previously unpublished results significant to the development of this field should be presented. The manuscripts must be submitted via the $J M R$ electronic submission system by July 1, 2019. Manuscripts submitted after this deadline will not be considered for the issue due to time constraints on the review process. Please select "Focus issue: Thermodynamics of Complex Solids" as the Focus Issue designation. Note our manuscript submission minimum length of $\mathbf{3 2 5 0}$ words, excluding figures, captions, and references, with at least 6 and no more than 10 figures and tables combined. Review articles may be longer but must be pre-approved by proposal to the Guest Editors via jmr@mrs.org. The proposal form and author instructions may be found at www.mrs.org/ jmr-instructions. All manuscripts will be reviewed in a normal but expedited fashion. Papers submitted by the deadline and subsequently accepted will be published in the Focus Issue. Other manuscripts that are acceptable but cannot be included in the issue will be scheduled for publication in a subsequent issue of JMR.

\section{jmr@mrs.org}




\section{MATERIALS RESEARCH SOCIETY ${ }^{\circledR}$}

\section{Board of Directors Officers}

Michael R. Fitzsimmons, President

Sean J. Hearne, Past President

Matt Copel, Vice President

Eric A. Stach, Secretary

David J. Parrillo, Treasurer

Todd M. Osman, Executive Director

\section{Directors}

Griselda Bonilla

Li-Chyong Chen

Dawnielle Farrar-Gaines

Sharon C. Glotzer

Claudia Gutiérrez-Wing

Sarah Heilshorn

Frances A. Houle

Monica Jung de Andrade

Sergei V. Kalinin
Kisuk Kang

Lincoln Lauhon

Paul C. McIntyre

Christopher Schuh

Rachel Segalman

Molly M. Stevens

Yusheng Zhao

Ehrenfried Zschech

\section{Publications Committee}

S.P. Baker, Chair

W. Weber, Editors Subcommittee

A.J. Hurd, New Publication Products Subcommittee

R.J. Nemanich, Publications Quality Subcommittee

\section{MRS Committee Chairs}

S. Mathur, Academic Affairs

J. L. MacManus-Driscoll, Awards

D. P. Norton, Government Affairs

T. Aselage, Meetings
S.M. Haile, Member Engagement

E. Kupp, Public Outreach

S.P. Baker, Publications

\section{MRS Headquarters}

T.M. Osman, Executive Director

J.A. Dillen, Director of Finance and Administration

D. Dozier, Director of Government Affairs

P.A. Hastings, Director of Meeting Activities

E.M. Kiley, Director of Communications

\section{Journal of Materials Research Founding Sponsors}

Allied-Signal Inc.

Xerox Corporation

\section{About the Materials Research Society}

The Materials Research Society (MRS ${ }^{\circledR}$ ) is a not-for-profit scientific association founded in 1973 to promote interdisciplinary goal-oriented basic research on materials of technological importance. Membership in the Society includes over 14,500 scientists from industrial, government, and university research laboratories in the United States and abroad.

The Society's interdisciplinary approach to the exchange of technical information is qualitatively different from that provided by single-discipline professional societies because it promotes technical exchange across the various fields of science affecting materials development. MRS sponsors two major international annual meetings encompassing many topical symposia, as well as numerous single-topic scientific meetings each year. It recognizes professional and technical excellence, conducts tutorials, and fosters technical exchange in various local geographical regions through Section activities and Student Chapters on university campuses.

Disclaimer: Authors of each article appearing in this Journal are solely responsible for all contents in their article(s) including accuracy of the facts, statements, and citing resources. Facts and opinions are solely the personal statements of the respective authors and do not necessarily represent the views of the editors, the Materials Research Society, or Cambridge University Press.
MRS journals maintain a proud tradition of editorial excellence in scientific literature. The Journal of Materials Research, the archival journal spanning fundamental developments in materials science, is published twenty-four times a year by MRS and Cambridge University Press. MRS Bulletin is a premier source for comprehensive research trends and a timely scan of professional activities. MRS Communications is a full-color letters and prospectives journal focused on groundbreaking work across the spectrum of materials research. MRS Energy \& Sustainability-publishes reviews on key topics in materials research and development as they relate to energy and sustainability. MRS Advances is a peer-reviewed online-only journal featuring impactful and emerging research, designed to reflect the way materials researchers work, write, publish and share their results.

The Journal of Materials Research is free electronically to all MRS regular and student members. See inside front cover for subscription rates for Journal of Materials Research.

MRS is an Affiliated Society of the American Institute of Physics and participates in the international arena of materials research through associations with professional organizations.

For further information on the Society's activities, contact MRS Headquarters, 506 Keystone Drive, Warrendale, PA 15086-7573; telephone (724) 779-3003; fax (724) 779-8313. 

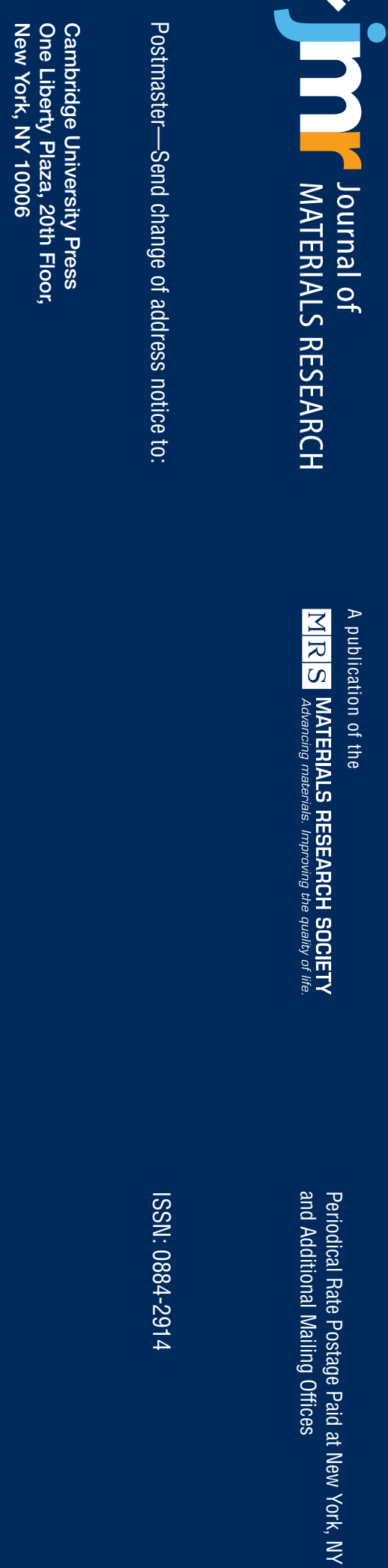